\title{
Editorial
}

\section{Long-Term Care: Where Do We Go From Here?}

François Béland is the outgoing editor-in-chief of the Canadian Journal on Aging - a position to which he has devoted the last six years after serving four years as Social Sciences editor. It is, therefore, fitting that he, with the help of his collaborator Delphine Arweiler, should end his term of office with a thoughtful and carefully developed conceptual framework for long-term care.

The two-part article in this issue of the Journal is also particularly timely for another reason. The well-orchestrated campaign to spotlight the deficit and the debt has made fiscal constraints on resources the prime focus of attention, with the result that it has sidelined and even obscured some fundamental questions which need to be addressed in order to inform the policy and strategic planning decisions in regards to long-term care.

Part I of the two-part article focusses on the elements of the framework for strategic planning, their interrelationships, their complexity and the policy and planning issues which they raise - a useful prelude to the exposition of the conceptual model proposed in Part II. In the process of discussing each element in the framework and of integrating them into the conceptual model, the authors highlight the major issues confronting longterm care, challenging gerontologists, policy-makers, planners, practitioners and the public to address them.

A system of values is basic to establishing priorities, defining objectives, choosing an organization to implement policies and mobilizing the resources necessary to achieve the objectives. Therefore, Béland and Arweiler start with the key question: what are the values which should underpin the policies and planning for long-term care? They note that, while recent provincial documents recognize that autonomy is fundamental to the quality of life of vulnerable elders, the absence of any discussion of values is disturbing since the ability of these elders to exercise that autonomy by accessing the resources needed to sustain their independence depends on societal values.

In a society based on individualistic values, access depends not on the need for help but on whether such help is "deserved". Thus, 19th century English almshouses, which served as nursing homes for vulnerable, indigent elders without informal support, differentiated between the "deserving" and "undeserving" poor by denying access to the "undeserving" whose conduct did not conform to the norms of the community or the church. In our time, individualistic values measure merit to access resources by an individual's ability to purchase the help he or she needs. Vulnerable elders who do not have enough money to purchase the services necessary to safeguard their 
autonomy are themselves responsible for the risks they take and for the consequences.

On the other hand, collectivist values, as the authors indicate, recognize that a society consists of interconnected individuals and that we all have a stake in sharing the cost of the resources which should be available when needed by any one of us. Access to services is then determined on the basis of the need for help. For the past three decades Canadians have been committed to collectivist values in regards to medical and hospital services. Opinion polls continue to indicate that most Canadians appreciate the consequences of having adopted these values. Furthermore, a recent threecountry study (Blendon \& Taylor, 1989) indicates that only 3 per cent of Canadians would prefer U.S. type health care policies which are based on individualistic values.

However, several current developments have been calling our collectivist values into question. Special interest groups and government statements have been using the public media not only to highlight the need for fiscal constraints due to deficits and debts but to promote the transformation of the health and social service system to one based on individualistic values. The rhetoric and the language used to convince the public of the need for this transformation increasingly focus attention on how much taxes we pay rather than on the benefits we derive from the public services for which the taxes are collected. The negative effects of these developments have been exacerbated by: (1) current and already-announced future reductions in federal transfer payments over the next few years under the new Canada Health and Social Transfer arrangements which now include the previous Established Program Financing Act (EPF) and the previous Canada Assistance Plan which helped provinces finance long-term care services; and (2) the efforts by some provinces to by-pass the requirements of the Canada Health Act, opening up the possibility for the development of a two-tier health care system. Together, these developments are reinforcing concerns about our commitment to the collectivist values underpinning long-term care. These concerns have not been allayed by recent provincial documents: in addition to virtually ignoring the question of values, their statements in support of increasing the choices available to long-term care clients, appear to be promoting an "every man for himself" orientation rather than supporting increases in the repertoire or amount of currently-available public resources to better serve vulnerable individuals.

Béland and Arweiler note the close relationship between values and the role of the state - the instrument by which societal values are translated into policy and planning decisions affecting all aspects of long-term care. The values adopted by a state and the extent to which it then chooses to be responsible for ensuring equitable access to services, allocating resources and determining priorities have a major impact on how organizational issues such as the role of the public/private sectors and the quality of care are addressed (see Figure 3 in Part I of the Béland and Arweiler paper). The recent strike by home care workers in Winnipeg, Manitoba illustrates not only 
the intimate connection between values and the role of the state but the relationship of both to ideology and the impact these relationships have on the organization and delivery of community care.

The strike followed the government's announcement that 25 per cent of the personal care services delivered by its workers in Winnipeg were slated for privatization within three months as the first step in the privatization of all services delivered in the city. The only reason given by the government for privatization was that the costs of community care were increasing - an increase which might have been expected in view of the growth in the numbers of elderly, the reduction in the ratio of nursing home beds to the older elderly, the downsizing of the hospital sector and the growth in the number of younger disabled adults choosing to remain in the community.

However, while the stated justification for privatization was presumably cost savings, government officials differed in their statements about whether and how much money would be saved. The Premier said the government expected to save $\$ 10 \mathrm{M}$. The Minister of Health said he was not expecting any savings. When questioned about the disparity in the two public statements, an Assistant Deputy Minister of Health said that $\$ 10 \mathrm{M}$ might be saved but no firm estimate could be made.

A coalition of senior and disabled advocacy groups, church groups and home care workers responded to the government's announcement and the strike which followed by convening a public meeting, sponsoring a demonstration and holding public hearings at the legislature. In response, the government presented no further reasons for privatization but simply reiterated that community care costs were rising and added that individuals assessed by the current continuing care case managers as requiring care would continue to receive the services they needed on the same basis as they had before. This assurance was given despite the disclosure by the Opposition that a Treasury Board document proposed to divide community care services into "core" services and two other unspecified categories which appeared to infer that not all the former services would continue to be delivered at no charge.

However, the results from Manitoba and other studies presented at these public events indicated that: (1) the average hourly costs to government for the home care workers in Winnipeg was lower than those in other urban centres such as Montreal, Toronto and Vancouver; (2) the annual cost per person receiving care was and continued to be modest as well as substantially lower than the alternatives; (3) the percentage of elderly receiving community care during the course of a year was stable at about 10 per cent over the last decade but the number of elderly had increased and the intensity of services provided to them had grown as the ratio of acute and longterm care facility beds declined; and (4) the turnover rates of home care workers in British Columbia was substantially higher for workers employed by private, for-profit companies (50\%) than for unionized workers $(32 \%)$ (Hollander, 1994) and both were higher than the Manitoba turnover rate provided by Manitoba Health officials. 
Representatives from seniors and younger disabled adults both individually and collectively focussed on the importance they attached to the continuity of personnel and quality of care. They indicated repeatedly that the same worker had been helping them for the last three to six years, that the worker was well-trained and had learned to adapt his/her performance of the sometimes very personal tasks to the individual's preferences. Home care recipients who were already receiving services from private company workers because of the strike reported that the replacement workers were untrained, that they had a different worker almost each time they were to receive the service and that they were dissatisfied with both the quality and continuity of the service provided. Neither the Minister nor his officials would provide any firm assurances that the standards or continuity of care would be maintained.

A number of lessons to be learned from the public debate during the fourweek strike confirm the relevance and importance of the Béland and Arweiler model for long-term care. First, the conflicting government statements about cost-savings and the absence of any evidence presented by its officials for privatization indicate that the government was more intent on reducing the state's role in long-term care than on saving money.

Second, the fact that the reduction of the state's role was not accompanied by any assurances about the quality of care and the continuity of care despite repeated requests by service recipients for such assurances highlights the significance ascribed by Béland and Arweiler to the relationship between the state's role and key organizational aspects of long-term care. In addition, two incidents in which community care users were encouraged to purchase more but unnecessary services by private company workers providing service during the strike may be indicative of a need to pay more attention to protecting service consumers from exploitation in defining standards of care when services are purchased from private companies. Since the elderly have generally been among the most likely subpopulation to be victimized by confidence men, they might become "ripe pickings" for private companies delivering community care unless safeguards are built in and audited.

Third, the involvement of community care consumers and the increasing involvement of primary caregivers in a number of actions during the strike indicate that the placement by Béland and Arweiler of the role of the family within the same orbit of issues as those relating to the role of the state makes sense. Furthermore, it reinforces the importance of the effects which this association has on organizational issues. Individual primary caregivers came forward to object to the government's decision and signs placed on private lawns indicated substantial support from caregivers and from the public for both the home care workers and for the continuation of the role of the state in community care. This support by caregivers' families and the public at large has implications for another key aspect of long-term care in the Béland and Arweiler model, namely, the distribution of resources because it suggests that the mobilization of public support might be one key to promoting the currently inadequate allocation of dollars for community 
care.

Fourth, the strike and the debate which followed highlight the seriousness and the urgency with which we should be grappling with these and each of the other important issues (e.g., the choice of models, the financing of long-term care) raised by Béland and Arweiler.

In addition to proposing a frame of reference within which to discuss longterm care issues, the ideas generated by the authors as they proceed to build the components into the model deserve special attention because they suggest new directions for community and long-term institutional care. Particularly intriguing are the reasons for and the possibilities of making the community care organization responsible for the funding and control not only of community care but also of long-term institutional resources and supportive housing on the grounds that it would be in the best position to assess the need for these resources and would be best placed to maximize their usefulness.

The two-part article makes a major contribution to long-term care in Canada by focussing attention on the key issues which will determine its future. We need to ensure that the issues will be addressed in the order of priority assigned to them by the authors and that their resolution produces a future responsive to the autonomy and needs of vulnerable elders.

\section{References}

Blendon, R.J., \& Taylor, H. (1989). Views on health care: Public opinion in three nations. DataWatch. Health Affairs, Spring, 149-157.

Hollander, M.J. (1994). The Costs and cost-effectiveness of continuing-care services in Canada. Queen's-University of Ottawa Economic Projects 94-10, Administration Health Sciences Medicine.

E. Shapiro 